\title{
Moderation is best: effects of grazing intensity on plant-flower visitor networks in Mediterranean communities
}

\author{
Amparo Lázaro,,${ }^{1,2,4}$ Thomas Tscheulin, ${ }^{1}$ Jelle Devalez, ${ }^{1}$ Georgios Nakas,${ }^{1}$ Anastasia Stefanaki, ${ }^{1}$ \\ Effie Hanlidou, ${ }^{3}$ and Theodora Petanidou ${ }^{1}$ \\ ${ }^{1}$ Laboratory of Biogeography and Ecology, Department of Geography, University of the Aegean, University Hill, GR-81100 \\ Mytilene, Greece \\ ${ }^{2}$ Department of Biodiversity and Conservation, Mediterranean Institute for Advanced Studies (UIB-CSIC), C/Miquèl Marquès \\ 21, 07190 Esporles, Balearic Islands, Spain \\ ${ }^{3}$ Laboratory of Systematic Botany and Phytogeography, Department of Botany, School of Biology, Aristotle University of \\ Thessaloniki, GR-54124 Thessaloniki, Greece
}

\begin{abstract}
The structure of pollination networks is an important indicator of ecosystem stability and functioning. Livestock grazing is a frequent land use practice that directly affects the abundance and diversity of flowers and pollinators and, therefore, may indirectly affect the structure of pollination networks. We studied how grazing intensity affected the structure of plant-flower visitor networks along a wide range of grazing intensities by sheep and goats, using data from 11 Mediterranean plant-flower visitor communities from Lesvos Island, Greece. We hypothesized that intermediate grazing might result in higher diversity as predicted by the Intermediate Disturbance Hypothesis, which could in turn confer more stability to the networks. Indeed, we found that networks at intermediate grazing intensities were larger, more generalized, more modular, and contained more diverse and even interactions. Despite general responses at the network level, the number of interactions and selectiveness of particular flower visitor and plant taxa in the networks responded differently to grazing intensity, presumably as a consequence of variation in the abundance of different taxa with grazing. Our results highlight the benefit of maintaining moderate levels of livestock grazing by sheep and goats to preserve the complexity and biodiversity of the rich Mediterranean communities, which have a long history of grazing by these domestic animals.
\end{abstract}

Key words: interaction diversity; Intermediate Disturbance Hypothesis; network properties; network structure; sheep and goat grazing; species-level indices.

\section{INTRODUCTION}

The structure of plant-pollinator networks may affect ecosystem stability and functioning (e.g., Thébault and Fontaine 2010, Tylianakis et al. 2010) and may contribute to biodiversity maintenance (Bascompte et al. 2006, Bastolla et al. 2009). Therefore, studying the structure of these mutualistic networks has allowed making predictions about the stability of communities against the loss of pollinators (Memmott et al. 2004, 2007, Bascompte et al. 2006, Aizen et al. 2012, Vieira et al. 2013, Domínguez-García and Muñoz 2015, Vieira and Almeida-Neto 2015) and assessing the effects of human disturbances, such as land use intensification (Marrero et al. 2014, Nielsen and Totland 2014) or plant invasions (Lopezaraiza-Mikel et al. 2007, Aizen et al. 2008). However, there are still not enough empirical data to test model predictions, and the mechanisms underlying the changes in network structure are far from understood.

Manuscript received 3 February 2015; revised 14 July 2015; accepted 21 July 2015. Corresponding Editor: A. K. Brody.

${ }^{4}$ E-mail: amparo.lazaro@imedea.uib-csic.es
Livestock grazing may indirectly affect the pollination process through changes in the abundance and diversity of flowers (e.g., Mayer et al. 2006, Roulston and Goodell 2011) and pollinators (e.g., Vulliamy et al. 2006, Xie et al. 2008, Kimoto et al. 2012). Although grazing can affect pollination networks (Vázquez and Simberloff 2003, Yoshihara et al. 2008a, Vanbergen et al. 2014), the effects of this disturbance on the structure of pollination interactions are still unclear. Vázquez and Simberloff (2003) found that cattle grazing modified a few highly frequent interactions in Argentinian communities, which presumably are important from a functional perspective. Vanbergen et al. (2014) compared ungrazed sites with cattle-grazed sites in Scotland and found that grazing increased the size, diversity, and generalization of networks. A similar result was found by Yoshihara et al. (2008a) when they compared ungrazed sites with highly grazed sites in Mongolia, whereas intermediate levels of grazing decreased network diversity and generalization (Yoshihara et al. 2008a). In the latter study, however, grazing gradients were associated with different types of grazers (sheep and goat vs. cow and horses) and therefore, these two effects could not be separated. 
The effects of grazing on the structure of pollination networks might strongly depend on grazing intensity. The Intermediate Disturbance Hypothesis predicts species diversity to be highest at intermediate levels of environmental stress due to offsetting effects of abiotic limitation and competitive exclusion (Intermediate Disturbance Hypothesis; Grime 1973, Conell 1978). If all the individuals have the same probability of interacting with other individuals ("interaction neutrality;" e.g., Vázquez et al. 2007, 2009), higher species diversity at intermediate grazing might result in larger generalization, higher diversity, and evenness of interactions, values that are considered indicative of robustness and community health (e.g., Dunne et al. 2002, Okuyama and Holland 2008, Thébault and Fontaine 2010, Blüthgen and Klein 2011, Tylianakis et al. 2010, Devoto et al. 2012, but see Vieira and Almeida-Neto 2015). However, it is difficult to predict how increased diversity at intermediate grazing would translate into link organization, i.e., modularity and nestedness, within the networks. Network modularity, i.e., weakly interlinked subsets of species consisting in strongly connected species, is expected to increase with species richness, while it might decrease with generalization (e.g., Lewinsohn et al. 2006, Olesen et al. 2007). On the other hand, it is still not clear how species richness relates to nestedness, i.e., the tendency of specialist species to only interact with generalist species. Some studies indicate positive relationships between network complexity and nestedness (Bascompte et al. 2003, Okuyama and Holland 2008, Bastolla et al. 2009), while others indicate negative relationships (James et al. 2012, Dalsgaard et al. 2013, Welti and Joern 2015).

Despite overall effects of grazing on the structure of plant-pollinator communities, there might be taxaspecific responses to grazing, since species differ in functional traits and have different susceptibilities to human disturbances; and consequently, the role of species can change along disturbance gradients (e.g., Nielsen and Totland 2014). Grazing is known to affect plant (Pykäla 2004, Navarro et al. 2006) and pollinator taxa (Sjödin et al. 2008, Kimoto et al. 2012, Murray et al. 2012) differently, which may result in changes in the number of interactions and selectiveness of flower visitors and plants in the networks, as grazing intensity varies. For instance, a larger number of interactions and lower selectiveness could be expected in ground-nesting bees compared to other bees as grazing intensities increase because grazing increases the availability of bare soil necessary for ground nesting (Petanidou and Ellis 1993, Potts et al. 2003, Vulliamy et al. 2006, Murray et al. 2012).

The Mediterranean Basin has a 10000-yr long history of livestock grazing (e.g., Petanidou and Ellis 1996, Blondel et al. 2010, Kizos et al. 2010) and is characterized by a high diversity of pollinators (e.g., Michener 1979, Petanidou and Ellis 1993, 1996, Nielsen et al. 2011). This high pollinator diversity has been attributed to the high floral diversity and the availability of bare soil in the area (Petanidou and Ellis 1996, Potts et al. 2003), but also to traditional Mediterranean land management (Potts et al. 2006, Nielsen et al. 2011), and particularly to extensive grazing (Petanidou and Ellis 1996). Despite that, few studies have directly linked grazing animals to pollinator communities in the Mediterranean (Petanidou and Ellis 1996, Potts et al. 2006, Vulliamy et al. 2006, Lázaro et al., 2016) and none has studied the effects of grazing on the structure of plant-flower visitor networks in this biodiversity hotspot area.

We explored how grazing intensity affected the structure of plant-flower visitor networks in 11 communities differing in grazing intensity on Lesvos Island, Greece. As far as we know, this is the first study considering the degree of grazing instead of the qualitative description of the community as ungrazed vs. grazed (or highly grazed) to study changes in the structure plantflower visitor networks. In a previous study on the same communities (Lázaro et al., 2016), we found hump-shaped relationships between grazing intensity and the abundance and diversity for most flower visitor groups, and therefore, our general expectation is that intermediate grazing might increase the conservation value to plant-flower visitor networks in these sites. Specifically, we tested (1) whether intermediate grazing intensity increases the size, generalization, modularity, diversity, and evenness of interactions in the plantflower visitor networks, and (2) whether the number of interactions and selectiveness of different taxa in the networks changes with grazing intensity, particularly, whether at higher grazing intensities, ground-nesting bees increase number of interactions and decrease selectiveness compared to other bees. We use the more conservative term of "floral visitor" to refer to potential pollinators caught on the flowers, because it was impossible to test the degree to which each insect visitor was an effective pollinator.

\section{Material And Methods}

\section{Study sites}

We conducted this study on 11 sites located in the southwestern part of Lesvos Island, in the north-eastern Aegean, Greece $\left(39^{\circ} 10^{\prime} \mathrm{N}, 26^{\circ} 20^{\prime} \mathrm{E}\right)$. Six of these study sites were located close to the village of Sigri, three close to the village of Eressos, and three close to the village of Vatousa (Fig. 1). All these sites correspond to phrygana, the main semi-natural habitat in the east Mediterranean, equivalent to the west Mediterranean garrigue. Phryganic habitats are dominated by low dimorphic and entomophilous shrubby or geophyte species, such as Cistus salviifolius L., C. creticus L., Origanum onites L., Thymbra capitata L., Sarcopoterium spinosum L., Centaurea spinosa L., and Asphodelus ramosus L., and are especially rich in bees, bee flies, and hoverflies (Petanidou and Ellis 


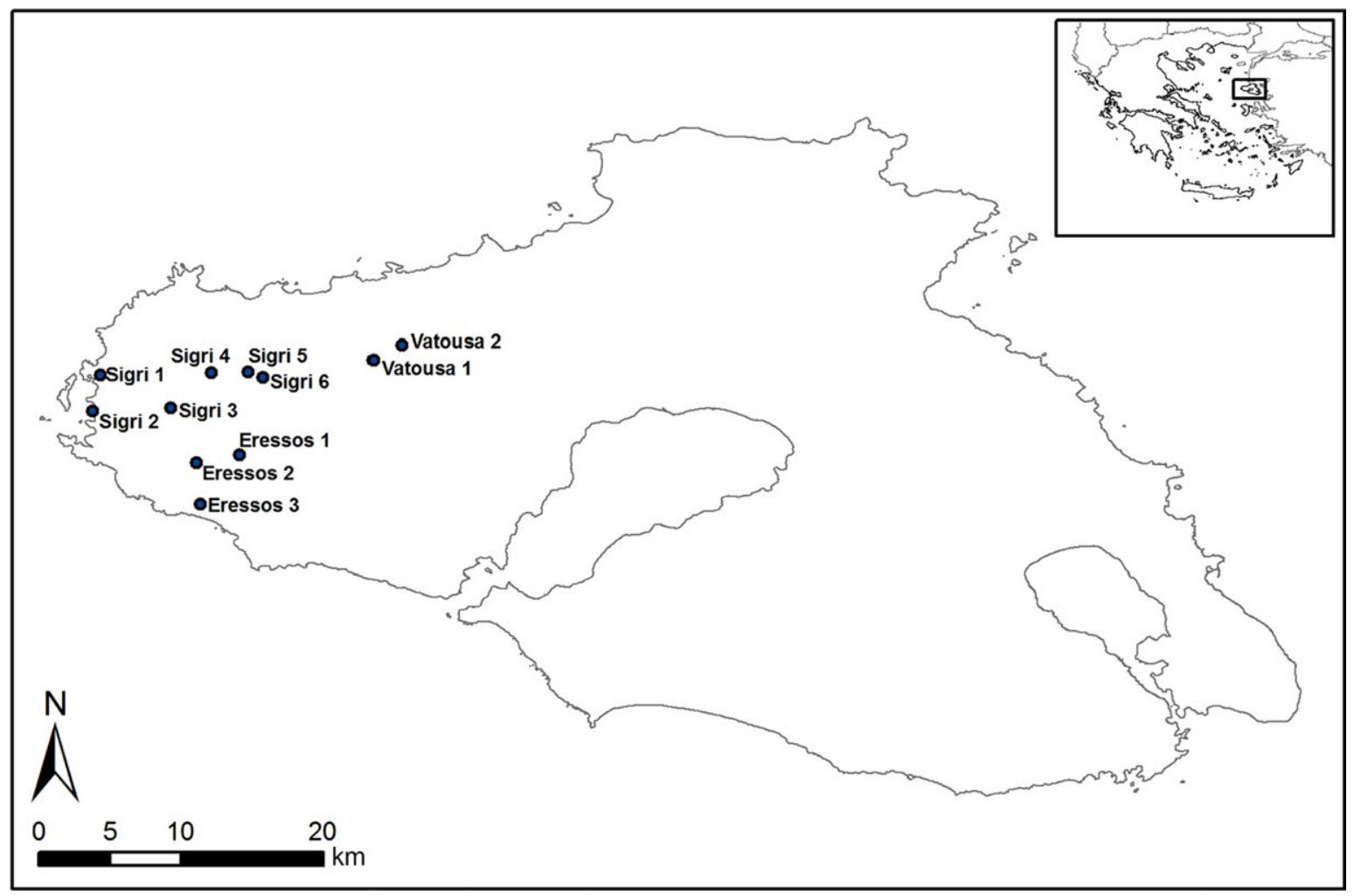

FIG. 1. A map of Lesvos Island (Greece) in the northeastern Aegean, with the location of the 11 study sites.

1993, Potts et al. 2006, Nielsen et al. 2011). Western Lesvos is an area dominated by livestock husbandry and intense grazing. Within the same area, there are scattered pieces of protected areas (petrified forest of Lesvos) where grazing is effectively banned. Our study took place in both protected and non-protected areas. Each study site was approximately 1 ha and was located within a wider area evenly managed by grazing. In this area, sheep grazing (and to a lesser extent goat grazing) occurs throughout the year but is considerably more intense during spring. There is a large variability in the intensity of grazing among these sites, and we found hump-shaped relationships between grazing intensity and the abundance and diversity of plants and of most flower visitor groups in them (Lázaro et al., 2016).

\section{Grazing intensity}

To estimate grazing intensity, we compared plant biomass inside and outside exclosures $(2 \times 2 \mathrm{~m})$ that were set up on each site $\sim 2$ months before the surveys started, i.e., in January 2012. During each sampling round, two squares $(0.5 \times 0.5 \mathrm{~m})$ were randomly selected at every site, one inside and one outside the exclosure. All aboveground plant biomass within the squares was collected, dried, and weighed $( \pm 0.01 \mathrm{~g})$ in order to compare biomass and calculate the grazing intensity. Sampled squares were marked in order to avoid their future resampling. Grazing intensity (\%) was estimated at each site and each sampling round as

$$
\left(1-\frac{\text { biomass of plants outside the exclosure }}{\text { biomass of plants inside the exclosure }}\right) \times 100 \text {. }
$$

\section{Insect visitation}

Each site was sampled using hand-netting on three occasions (rounds) within the main flowering season in 2012: in late March-early April (round 1), in late Aprilearly May (round 2), and in later May-early June (round 3). Samplings were carried out under good weather conditions: temperature $>15^{\circ} \mathrm{C}$, sunshine, and no wind $(<4 \mathrm{~m} / \mathrm{s})$. The hand-netting survey consisted of a $120 \mathrm{~min}$ random walk during which we collected any insect observed visiting a flower and contacting its reproductive parts, stopping the timer any time attention was distracted from the flowers (e.g., while transferring caught insects into vials). Surveys were conducted between 10:00 and 16:30. Time allocated to each plant species was proportional to its abundance. Collected insects were transferred to vials and refrigerated if they were to be processed within $24 \mathrm{~h}$, otherwise deep frozen until pinning. After processing in the laboratory, the specimens were identified to species level (when necessary, with the help of European specialists) and deposited in the database of the Melissotheque of the Aegean (Petanidou et al. 2013). 


\section{Flower cover}

Flower cover measurements were conducted on 25 $1 \times 1 \mathrm{~m}$ squares randomly selected in every round and site, within the area where insects were collected. The total number of functional reproductive units, i.e., flowers or inflorescences depending on the species ("flowers" hereafter), for each plant species was counted within these squares. Per site and round, we calculated flower abundance as the average number of flowers $/ \mathrm{m}^{2}$ and floral richness as the number of flowering species. Plant specimens were identified using Davis (1965-1985) and deposited in the Herbarium of the Laboratory of Biogeography and Ecology of the University of the Aegean.

\section{Network indices}

For each site and round, we created a matrix with the sum of recorded visits for every pairwise insect-plant interaction and calculated network architecture parameters using the bipartite package (Dormann et al. 2008) in R 2.15.3 (R Development Core Team 2008). We used separate interaction matrices for each sampling round and site to include within-site grazing variability in the models, but also because aggregating interaction data in time can bias the metrics derived from them (Medan et al. 2006) due to phenological variability and forbidden links arising from non-overlapping phenophases (Olesen et al. 2011). Whenever possible, we used quantitative descriptors of the networks since excluding interaction strength may lead to the description of variations with little relevance to ecosystem function (Bersier et al. 2002, Blüthgen et al. 2006, Pocock et al. 2011).

Network properties. - To describe network properties, we used the following indices: (1) Number of species and number of links in the networks, as measures of network size; (2) Linkage density (weighted), as the mean number of links per species weighted by the frequency of interactions (Bersier et al. 2002, Dormann et al. 2009). We chose this index to describe generalization as suggested by Tylianakis et al. (2010) when networks differ in size; (3) Interaction diversity and interaction evenness, Shannon's diversity, and evenness of interactions (Dormann et al. 2009); (4) Modularity, as the modularity of weighted bipartite matrices (function "computeModules"; Dormann and Strauss 2014). Modularity describes the extent to which the networks are organized into subsets composed by strongly interlinked species which are weakly connected to other subsets (e.g., Olesen et al. 2007); (5) Nestedness, as weighted NODF (nestedness metric based on overlap and decreasing fill), a quantitative index for nestedness in which high values indicate nestedness, i.e., high tendency for specialist species to interact with generalist ones in the mutualistic networks (Almeida-Neto et al. 2008, Almeida-Neto and Ulrich 2011).

The degree and selectiveness ( $\left.d^{\prime}\right)$ of flower visitor and plant taxa in the networks. - To detect whether flower visitor and plant taxa changed their role as grazing intensity increased, we calculated two indices at the species level: species degree, as the sum of interactions per species, and selectiveness $\left(\mathrm{d}^{\prime}\right)$, as the standardized specialization of each species based on its discrimination from random selection of partners (Blüthgen et al. 2006), which ranges from 0 (no specialization) to 1 (perfect specialist). We used these indices calculated at the species level (Dormann 2011) to compare whether different plant families, insect guilds, and nesting habits responded differently to grazing intensity.

\section{Statistical analyses}

All the statistical analyses reported here were conducted in R 2.15.3 (R Development Core Team 2008). To study the effect of grazing intensity on network structure, we used generalized linear mixed models (GLMM; library lme4), with site as a random variable to avoid pseudoreplication, grazing intensity as a continuous, and round as a categorical fixed variable. Flower abundance was also included as a predictor variable since it might influence network structure independently; however, we did not include flower richness, because it was highly correlated with the number of plant species in the network. We hypothesized that the highest diversity at intermediate grazing levels (Grime 1973, Conell 1978) might differently affect the structure of networks at intermediate grazing intensities, and therefore, we included the variable "grazing intensity" both as a linear and quadratic term in the analyses. To avoid collinearity between these two terms, we first standardized the variable "grazing intensity" to $\bar{x}=0$ and $\sigma=1$ and then we calculated its quadratic term (Quinn and Keough 2002). In the models in which the network parameters were calculated at the species level, we added the species as an additional random factor, which was included in the model as nested within site. In these models, we checked whether the degree and selectiveness $\left(d^{\prime}\right)$ of the species in the networks differed depending on the insect guild (only bees, wasps, beetles, flies, and butterflies included due to low sample size in the other guilds) or the plant family (only the four most common families) in separate analyses, by specifically testing the interactions between grazing intensity and insect guild or plant family. Additionally, we tested whether bee-nesting habit was associated with their response to grazing, since ground-nesting bees are expected to be favored by increased bare soil after grazing (e.g., Petanidou and Ellis 1993, Potts et al. 2003, Vulliamy et al. 2006, Murray et al. 2012). Before the analyses we used Moran's I (R library ncf; Bjørnstad and Falck 2001) to check for any spatial correlation in the data or in the residuals of the models (without random factor); neither the data nor the residuals showed any spatial correlation, indicating that our approach with mixed models 
was appropriate. We also ran variation inflation factor (VIF) analyses to identify collinear predictor variables that should be removed from further analyses (Zuur et al. 2009). VIF values were smaller than three for all variables, so none of the predictors needed to be removed (Zuur et al. 2009). We used Poisson distribution and log link function for the analyses of the number of species and links, and for species degrees, after checking that the models were not overdispersed (i.e., in all cases the ratio between the residual deviance to residual degrees of freedom was $<1.1$; Zuur et al. 2009). Selectiveness (d) was analyzed using a Gamma distribution with log link function, due to the nature of the data. Gaussian distributions were used for the rest of the indices analyzed, using identity or log link functions depending on the nature of the data. We used Akaike's information criterion corrected for small sample sizes, AICc, (library sme; Hurvich and Tsai 1989, Burnham and Anderson 2004) to select best models among the set of combinations of predictor variables and to test whether model fit was better when including random intercept, random slope, or both (in all cases, best models included only random intercept).

The analyses at the network level were performed after controlling for the varying number of species sampled across different sites and rounds (e.g., Gotelli and Colwell 2001, Vanbergen et al. 2014). For that, we set network size to the smallest one sampled, by randomly deleting insect species from each network (function sample; library bipartite in R) and recalculating network parameters. We repeated this procedure 1000 times and the mean of these values was used as a standardized value for each index (Vanbergen et al. 2014). Hereafter, we use the term "raw networks" to refer to non-standardized networks, whereas the term "standardized networks" is used to refer to the networks standardized by the size. To compare nestedness and modularity across networks of different size and complexity, we estimated a standardized nestedness $z$ score (Almeida-Neto et al. 2008, Ulrich et al. 2009, Vanbergen et al. 2014), and a standardized modularity $z$ score (Dormann and Strauss 2014). Standardized $z$ scores were calculated as: $Z=[x-\mu] / \sigma$, where $x$ is the nestedness/modularity value for our network, $\mu$ is the mean nestedness/modularity value, and $\sigma$ is the standard deviation for 1000 networks of same size as the focal one and randomly generated using a null model that fixes total number of interactions (function nullmodel; method; r2d; library bipartite). Mean values of variables and model estimates are accompanied by their standard error (SE) throughout the text.

\section{RESULTS}

Our sites had a total of 84 plant (25 families) and 239 insect species. Overall, we recorded 2707 insect visits to plants, including 1162 visits by bees (124 species), 644 by beetles (13 species), 457 by flies ( 47 species), 330 by butterflies (16 species), 109 by wasps (38 species), and five by Neuroptera (one species). The values of grazing intensity for each site and round are shown in Table 1.

\section{Effects of grazing on network properties}

The number of species and the number of links in the networks were highest at intermediate grazing intensities (Table 2A and B, Fig. 2). The number of species and the number of links also increased significantly with flower abundance (slope: $0.002 \pm 0.001$, for both species and links; Table 2A and $\mathrm{B}$ ).

Linkage density, interaction diversity, interaction evenness, and modularity were highest at intermediate grazing intensities in the raw networks (Table 2C-F, Fig. 3). Linkage density also differed among rounds, being higher in round 3 than in round 1 and 2 $(3.03 \pm 0.32,2.45 \pm 0.26$, and $2.56 \pm 0.25$, respectively; Table 2C).

The effect of grazing on linkage density and modularity disappeared when standardizing by network size (Table 2C, F), whereas the results for interaction diversity, interaction evenness and nestedness were maintained (Table 2D, E, G, Fig. 3B and C).

\section{Effects of grazing on the degree and selectiveness $\left(\mathrm{d}^{\prime}\right)$ of flower visitor and plant taxa in the networks}

Flower visitor taxa. - Although the best model for the degree of flower visitors showed a hump-shaped relationship with grazing (estimate grazing intensity2: $-0.571 \pm 0.827)$, this relationship was non-significant (Table 3A), and therefore none of the predictor variables affected flower visitor degree significantly. Insect species selectiveness $\left(d^{\prime}\right)$ varied with grazing intensity differently depending on the flower visitor guild (Table 3A): $d^{\prime}$ decreased with grazing intensity for all the guilds except for butterflies, which showed an inverse hump-shaped relationship with grazing intensity, sharply increasing with high grazing (Fig. 4A). Insect species $d^{\prime}$ also

TABLE 1. Grazing intensities estimated per site and round.

\begin{tabular}{lccc}
\hline Site & Round 1 & Round 2 & Round 3 \\
\hline Eressos1 & 51.9 & 43.8 & 31.3 \\
Eressos2 & 48.3 & 32.4 & 61.5 \\
Eressos3 & 42.9 & 17.4 & 69.2 \\
Sigri1 & 0.0 & 2.1 & 11.1 \\
Sigri2 & 7.0 & 0.0 & 7.4 \\
Sigri3 & 10.2 & 0.0 & 0.0 \\
Sigri4 & 76.9 & 52.9 & 67.9 \\
Sigri5 & 52.9 & 27.6 & 52.1 \\
Sigri6 & 50.6 & 21.1 & 29.2 \\
Vatousa1 & 52.6 & 37.0 & 26.7 \\
Vatousa2 & 30.0 & 50.0 & 60.6 \\
\hline
\end{tabular}


TABLE 2. Results of generalized linear mixed models relating network indices to four predictor variables (grazing intensity, grazing intensity ${ }^{2}$, flower abundance, and round) and their combinations, for the raw and the standardized networks..

\begin{tabular}{|c|c|c|c|}
\hline Network index & Grazing intensity $^{2}$ & Round & Flower abundance \\
\hline (A) Number of species & $\chi_{1}^{2}=7.19, P=\mathbf{0 . 0 0 7}$ & & $\chi_{1}^{2}=12.22, P=\mathbf{0 . 0 0 0 5}$ \\
\hline (B) Number links & $\chi_{1}^{2}=2.73, P=\mathbf{0 . 0 0 6}$ & & $\chi_{1}^{2}=3.44, P=\mathbf{0 . 0 0 1}$ \\
\hline \multicolumn{4}{|l|}{ (C) Linkage density } \\
\hline Raw networks & $\chi_{1}^{2}=4.58, P=\mathbf{0 . 0 3 2}$ & $\chi_{2}^{2}=6.10, P=\mathbf{0 . 0 4 7}$ & $\chi_{1}^{2}=8.82, P=0.065$ \\
\hline Standardized networks & $\chi_{1}^{2}=0.17, P=0.676$ & & \\
\hline \multicolumn{4}{|l|}{ (D) Interactions diversity } \\
\hline Raw networks & $\chi_{1}^{2}=13.61, P=\mathbf{0 . 0 0 0 2}$ & & \\
\hline Standardized networks & $\chi_{1}^{2}=13.87, P=\mathbf{0 . 0 0 0 2}$ & & \\
\hline \multicolumn{4}{|l|}{ (E) Interactions evenness } \\
\hline Raw networks & $\chi_{1}^{2}=7.98, P=\mathbf{0 . 0 0 5}$ & & \\
\hline Standardized networks & $\chi_{1}^{2}=5.12, P=\mathbf{0 . 0 2 4}$ & & \\
\hline \multicolumn{4}{|l|}{ (F) Modularity } \\
\hline Raw networks & $\chi_{1}^{2}=10.54, P=\mathbf{0 . 0 0 1}$ & & \\
\hline$z$ score & $\chi_{1}^{2}=0.21, P=0.645$ & & \\
\hline \multicolumn{4}{|l|}{ (G) Nestedness } \\
\hline Raw networks & $\chi_{2}^{2}=0.43, P=0.511$ & $\chi_{2}^{2}=0.31, P=0.858$ & \\
\hline$z$ score & $\chi_{2}^{2}=1.77, P=0.184$ & $\chi_{2}^{2}=6.95, P=\mathbf{0 . 0 3 1}$ & \\
\hline
\end{tabular}

Notes: Separate models were fitted to each index. The significance (based on likelihood ratio tests; LRT) of the variables included in the best model (selected using AICc) is given; the linear term of grazing intensity was also included during model selection, but did not appear in any of the best models. Significant $P$ values are marked in bold.
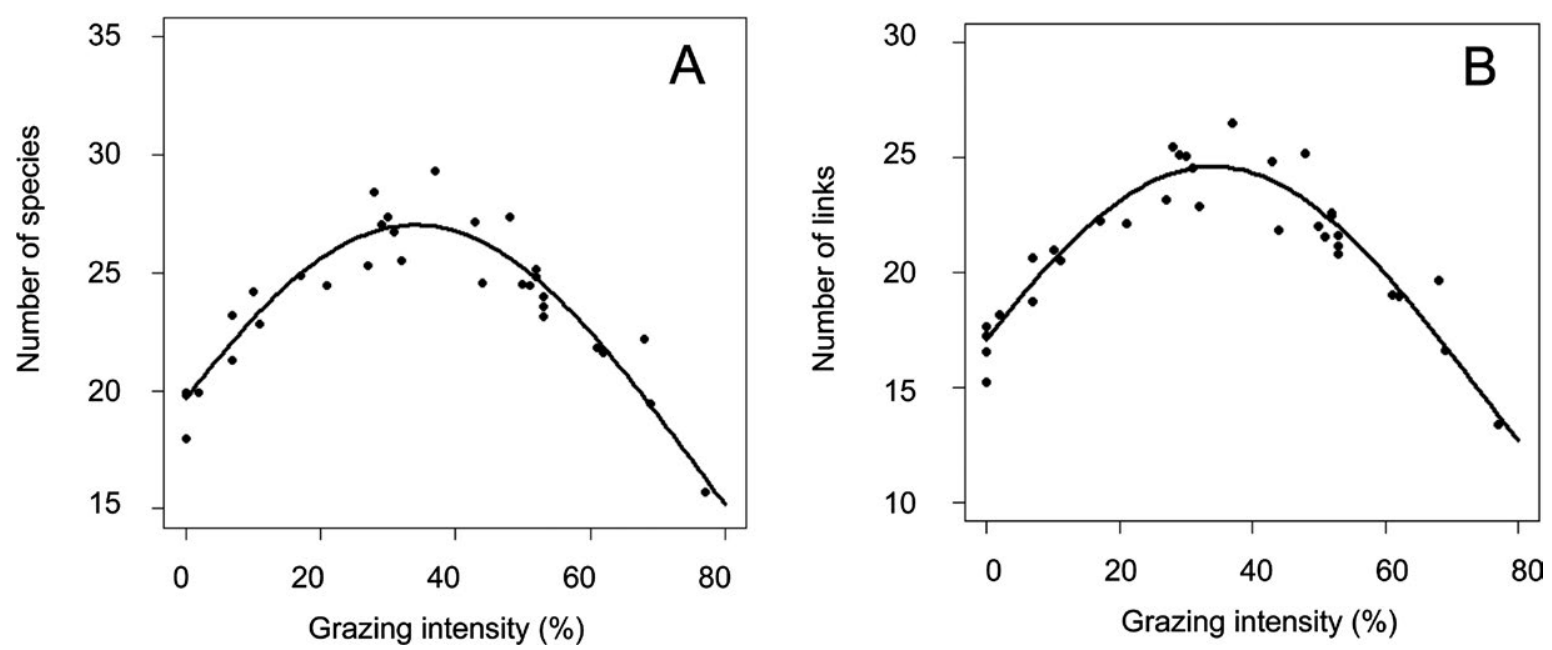

FIG. 2. Network size: the relationships between grazing intensity and (A) the number of species, and (B) the number of links in the networks. Lines represent the estimates of the best models, and the circles the partial residuals in raw networks.

decreased along the season $(0.43 \pm 0.02,0.39 \pm 0.02$, and $0.27 \pm 0.02$, for round 1,2 and 3 , respectively; Table $3 \mathrm{~A})$.

The degree and selectiveness $\left(d^{\prime}\right)$ of bees did not depend on nesting habit, since this variable did not appear as a significant variable in any of the best models. In addition, the results for the bees agreed with those found when analyzing all the flower visitors. Thus, bee degree was not affected by any of the predictor variables (best model, nesting behavior: $\left.\chi_{1}^{2}=0.51 ; P=0.48\right)$, and $d^{\prime}$ in the bees decreased with grazing intensity (slope: $-0.311 \pm 0.091 ; \chi_{1}^{2}=8.43$; $P=0.004)$ and also along the rounds $\left(\chi_{2}^{2}=21.49\right.$; $P<0.0001)$.

\section{Plant taxa}

Plant degree differed among families (Table 3B), with Lamiaceae species having the highest degree $(4.83 \pm 0.83)$ and Fabaceae, the lowest $(2.39 \pm 0.37)$. Plant species degree varied with grazing intensity differently, depending on the plant family (Table 3B, 

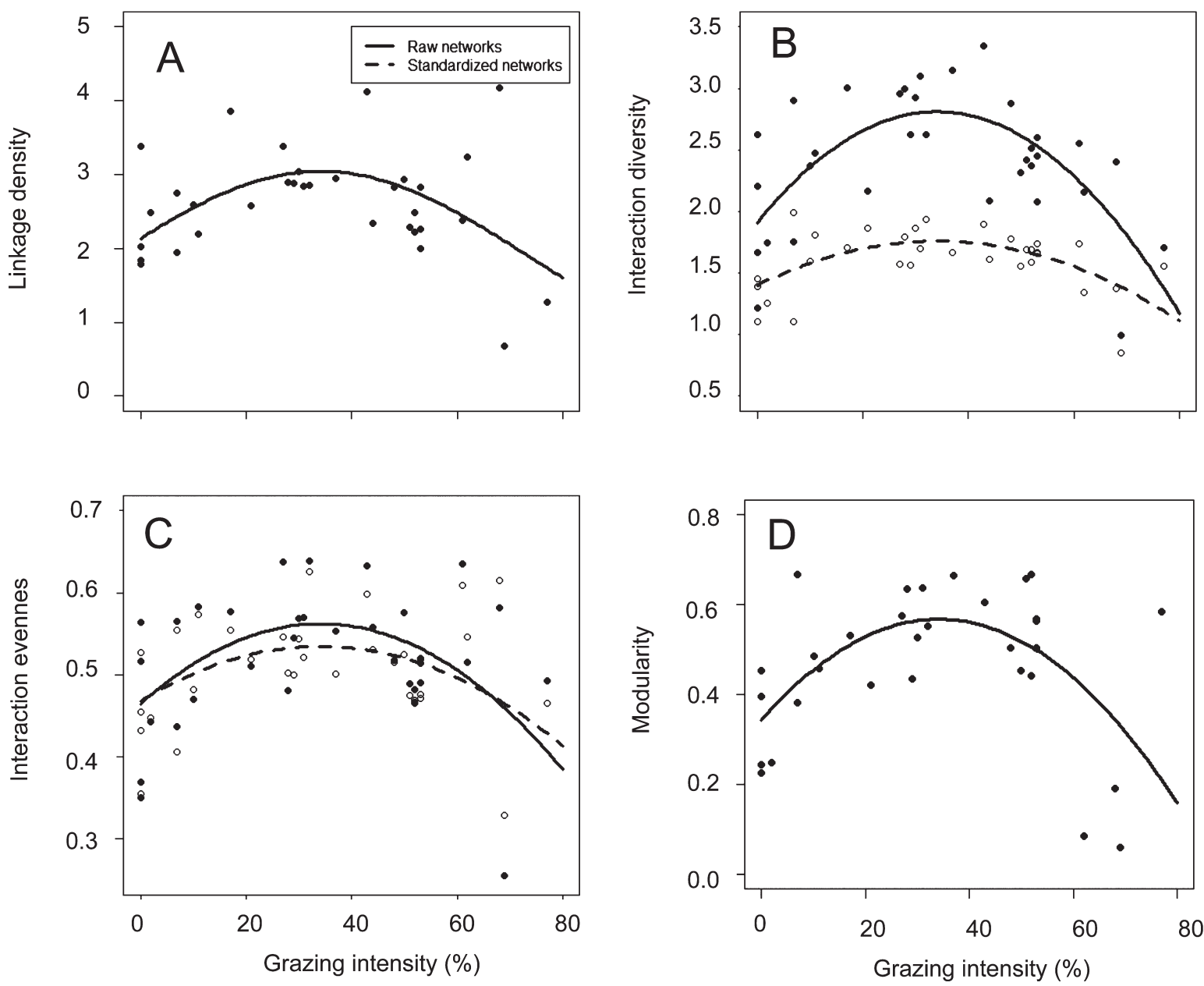

FIG. 3. Network properties: the relationships between grazing intensity and (A) linkage density, (B) interaction diversity, (C) interaction evenness, and (D) modularity. Only significant relationships between grazing intensity and the indices are depicted. Continuous lines and solid circles represent the estimates and partial residuals for the raw networks, respectively, and dashed lines and open circles represent the estimates and partial residuals for the standardized networks, respectively, whenever these relationships were significant.

Fig. 4B): the degree decreased with grazing intensity for Brassicaceae, and increased for Lamiaceae and less for Fabaceae. Best model for plant species $d^{\prime}$ was the quadratic term of grazing intensity, but it was not significant (Table 3B), and therefore, none of the predictor variables affected plant species $d^{\prime}$.

\section{Discussion}

Intermediate livestock grazing by sheep and goats increased the size, generalization, and complexity of plant-flower visitor networks, which might in turn confer conservation value to these communities. Despite general response at the network level, the degree and selectiveness of particular flower visitor and plant taxa on the networks responded differently to grazing intensity, presumably as a consequence of changes in the abundance of different taxa with grazing.

\section{How does grazing affect the structure of plant-flower visitor networks?}

The effect of grazing on the structure of plant-flower visitor networks depended on grazing intensity. As expected, at intermediate grazing intensities networks were larger, more generalized, more modular, and with more diverse and even interactions. A priori, it could seem slightly counterintuitive that networks at intermediate grazing are both more generalist and more modular. However, this double effect is directly related to the influence that grazing has on network size (these effects disappeared in standardized networks), because increasing the number of species may enhance the opportunities of interaction (e.g., Vázquez et al. 2007, 2009) and because modularity is higher in larger networks (Olesen et al. 2007), as more species may increase the chances of creating more modules of strongly interlinked species. 
TABLE 3. Best models explaining the effect of grazing intensity on the degree and selectiveness (d') of flower visitor guilds and plant families in the networks.

\begin{tabular}{|c|c|c|}
\hline Model & Degree & $\begin{array}{c}\text { Selectiveness } \\
\left(d^{\prime}\right)\end{array}$ \\
\hline \multicolumn{3}{|l|}{ (A) Flower visitor guilds } \\
\hline Grazing intensity $^{2}$ & $\begin{aligned} \chi_{1}^{2} & =0.48, \\
P & =0.489\end{aligned}$ & \\
\hline Guild & & $\begin{aligned} \chi_{3}^{2} & =2.36 \\
P & =0.502\end{aligned}$ \\
\hline Guild $\times$ grazing intensity & & $\begin{aligned} \chi_{4}^{2} & =12.60 \\
P & =\mathbf{0 . 0 1 3}\end{aligned}$ \\
\hline Guild $\times$ grazing intensity ${ }^{2}$ & & $\begin{aligned} \chi_{4}^{2} & =12.86 \\
P & =\mathbf{0 . 0 1 2}\end{aligned}$ \\
\hline Round & & $\begin{aligned} \chi_{2}^{2} & =23.27 \\
P & <\mathbf{0 . 0 0 0 1}\end{aligned}$ \\
\hline \multicolumn{3}{|l|}{ (B) Plant families } \\
\hline Family & $\begin{aligned} \chi_{3}^{2} & =11.57 \\
P & =\mathbf{0 . 0 0 9}\end{aligned}$ & \\
\hline Family $\times$ grazing intensity & $\begin{aligned} \chi_{3}^{2} & =8.69 \\
P & =\mathbf{0 . 0 3 4}\end{aligned}$ & \\
\hline Grazing intensity ${ }^{2}$ & & $\begin{aligned} \chi_{1}^{2} & =1.44 \\
P & =0.231\end{aligned}$ \\
\hline
\end{tabular}

Notes: The significance (based on likelihood ratio tests; LRT) of the variables included in the best model (selected using AICc) is given; when an interaction was significant, statistics are only given for the interaction, but the continuous variables participating in the interactions were also included in the models. Significant $p$ - or $P$-values are marked in bold.

The network properties found to be highest at intermediate grazing pressure were those that have been predicted to confer stability or increased function to a system and are therefore of greatest interest for conservation (Tylianakis et al. 2010). Higher interaction diversity and evenness are indicative of good community health (Tylianakis et al. 2010, Devoto et al. 2012), high generalization and greater species redundancy are usually assumed to confer robustness against environmental stressors and provide conservation value (Dunne et al. 2002, Memmott et al. 2004, Thébault and Fontaine 2010, Blüthgen and Klein 2011), and high modularity may help to slow the spread of disturbances (e.g., Krause et al. 2003). However, indirect assessments of stability based on network structure depend on the model used to evaluate it (e.g., Dunne et al. 2002, Memmott et al. 2004, Thébault and Fontaine 2010, Vieira and Almeida-Neto 2015), and therefore, additional work is needed to clarify whether the higher diversity and evenness of interactions at intermediate grazing makes these networks more persistent and resilient against perturbations. Moreover, the effects on changes in plant-visitor interactions will ultimately depend on the relative importance of particular taxa to plant reproduction.

Previous studies have shown that cattle grazing modified a few highly frequent interactions (Vázquez and Simberloff 2003) and increased the size, diversity, and generalization of the networks (Vanbergen et al. 2014); however, in these studies ungrazed sites were compared to grazed ones and the effect of actual grazing intensity was not considered. Our results add to the above two study conclusions, by elucidating the range of grazing that is needed to achieve the best results when employing grazing as a management tool. On the other hand, the study of Yoshihara et al. (2008a) included three grazing intensity levels and found patterns that disagree with ours: less diverse and less generalized networks at intermediate grazing intensities. There are several reasons why our results may differ. First, the study systems are considerably different: while we analyzed very species-rich sites, they studied relatively species-poor grasslands. Second, the difference may be also related to the Mediterranean nature of our study systems, which have
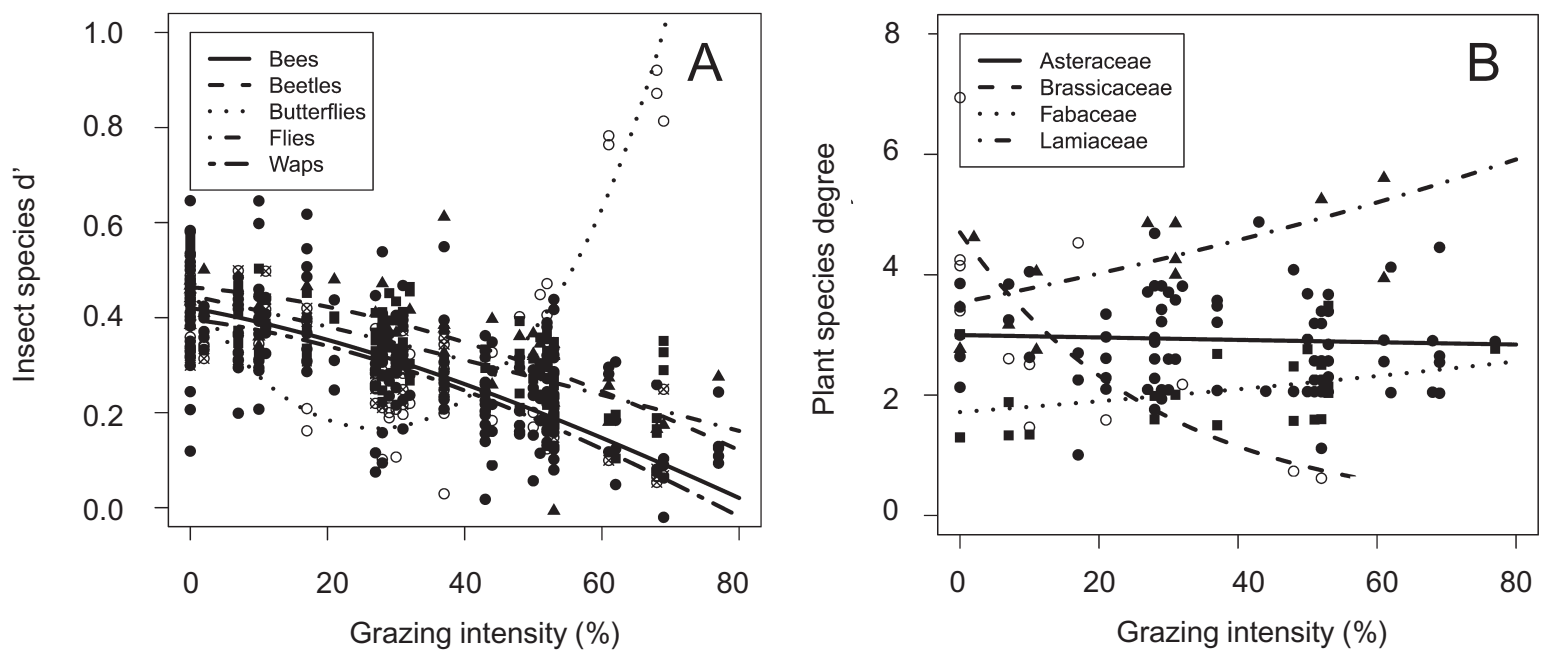

FIG. 4. The degree and selectiveness $\left(d^{\prime}\right)$ of flower visitor and plant taxa: the relationships between grazing intensity and (A) insect species $d^{\prime}$, and (B) plant species degree. When there were significant interactions including grazing intensity, the estimates are shown for each level of the factor. Circles, triangles, and squares represent partial residuals. 
been shaped by sheep and goat grazing for at least the last 10000 years (Petanidou and Ellis 1996, Blondel et al. 2010, Kizos et al. 2010). Indeed, the Intermediate Disturbance Hypothesis has been repeatedly confirmed to apply in grazed Mediterranean systems for many aspects of community structure, such as heterogeneity in vegetation composition (Koniak and Noy-Meir 2009) and plant (Naveh and Whittaker 1979), mammal (Gonçalves et al. 2012), and insect diversity (Kati et al. 2012, Kaltsas et al. 2013). Third, in Yoshihara et al.'s (2008a) study, grazing intensity levels were related to different types of grazers (sheep and goat, and cow and horses), and therefore, they could not distinguish between the effect of intensity and type of animal grazer. It is possible that the type of grazer affects the outcome of the disturbance differently because grazers differ in the composition and flexibility of their diet (e.g., Migongobake and Hansen 1987, Yoshihara et al. 2008b). We used sites with a large gradient of grazing intensities and same grazers, and our results may therefore more accurately reflect the effect of grazing intensity.

We did not find any significant relationship between nestedness and grazing intensity. Different studies have shown contrasting relationships between network size and nestedness (e.g., Okuyama and Holland 2008, Bastolla et al. 2009, James et al. 2012, Dalsgaard et al. 2013, Welti and Joern 2015), and therefore, we did not have a clear prediction about how intermediate grazing intensity might affect nestedness. Vanbergen et al. (2014) found grazing to affect nestedness in opposite directions, depending on whether the networks were standardized or not, which suggests that if an effect of grazing on networks exists, it may be complex. Interestingly, although grazing affected linkage density and modularity indirectly, through its effect on network size, other network properties (interaction diversity and interaction evenness) were maintained when networks were standardized by the size. Therefore, some of the structural properties that grazing confers are not exclusively related to an increase in network size, contrary to what was shown for cattle-grazed sites in Scotland (Vanbergen et al. 2014). This result is remarkable because the most direct effect of grazing is on network size (Fig. 2), which is known to affect many network properties (e.g., Goldwasser and Roughgarden 1997, Bersier et al. 1999). Perhaps grazing influences interaction diversity and evenness independently of network size by affecting the abundance of more generalist species.

\section{Does grazing affect the specialization of flower visitor and plant taxa differently?}

The degree and selectiveness $\left(d^{\prime}\right)$ of certain taxonomic groups changed as grazing intensity increased, in line with other studies that have shown changes in species' roles along gradients of land use (Nielsen and Totland 2014). In the plants, we did not find grazing intensity to affect $d^{\prime}$. However, plant families responded differently to grazing with changes in their degree. The degree is the most basic measure of specialization, and in pollination systems, the most generalized species are usually network keystone species (e.g., Martín González et al. 2010). We have found that as grazing intensity increased, the degree of some families also increased (viz. Fabaceae and Lamiaceae, especially for Lamiaceae; Fig. 4B), while the degree of others decreased (viz. Brassicaceae; Fig. 4B). Fabaceae and Lamiaceae are visited mainly by bees which are more positively influenced by grazing compared to the other guilds (Lázaro et al., 2016); thus, an increase in the abundance of bees may result in a larger number of interactions in the species of these families. On the other hand, the strong decrease in the degree of Brassicaceae is related to a decrease in the abundance of this family as grazing intensity increased (slope: $-11.04 \pm 3.14 ; t=-3.52, P=0.0004$ ) and may reflect its susceptibility to grazing.

Regarding the flower visitors, we expected groundnesting bees to increase their degree and decrease their selectiveness more than other bees in response to grazing intensity, because grazing increases the availability of bare soil necessary to construct the nests of these insects (Petanidou and Ellis 1993, Potts et al. 2003, Vulliamy et al. 2006, Murray et al. 2012). However, we did not find any difference between the degree and selectiveness $\left(d^{\prime}\right)$ of ground-nesting bees and the other bees in the networks. Instead, we found differences in the selectiveness $\left(d^{\prime}\right)$ of flower visitor guilds in relation to grazing. The relationship between grazing intensity and selectiveness $\left(d^{\prime}\right)$ followed an inverse hump-shaped relationship in butterflies (Fig. 4A), indicating that intermediate grazing makes these animals less selective in their use of plant species. However, for the rest of insects, $d^{\prime}$ decreased with grazing intensity. This means that insect species are less selective as grazing intensity increases (Fig. 4A). Although there is a concordance between the increase in linkage density and the decrease in $d^{\prime}$ from null to intermediate grazing, the very low $d^{\prime}$ (very low selectiveness) at high grazing intensity could seem a priori in disagreement with the low linkage density under high grazing intensity (Fig. 3A). However, this might be because, although $d^{\prime}$ expresses specialization, it is very conservative for cases where species are specialized on a commonly utilized niche (Blüthgen et al. 2006, Blüthgen 2010), as it constitutes a local measure of the deviation from a completely neutral configuration of associations (Blüthgen et al. 2006, Blüthgen 2010). When grazing intensity is high, there are very few plant species left, and therefore insects specialize on very commonly utilized plants, which results in low $d^{\prime}$ but also low linkage density at high grazing intensities. The relationship between $d^{\prime}$ and species function in the networks is still unclear (Blüthgen 2010), but this measure of specialization is largely robust against variation in matrix size, shape, and sampling effort, which allows direct comparisons across networks (Blüthgen et al. 2006), and its use in network analyses have been highly 
recommended (e.g., Blüthgen 2010, Pocock et al. 2011). However, $d^{\prime}$ has some limitations (Blüthgen et al. 2006) that should be considered when interpreting our results: first, the calculation of $d^{\prime}$, as well as other niche breadth indices, is based on the implicit assumption that each species adjusts its interactions according to the availability of partners (irrespectively of morphological or behavioral constraints; e.g., Olesen et al. 2011); second, species-wise specialization measures such as $d^{\prime}$ may be sensitive to the behavior of other species, and therefore, any systematic sampling bias (e.g., taxonomic focus within a guild) might affect the conclusions of comparisons within or across networks.

\section{Conclusions}

The abandonment of traditional extensive agriculture has led to an increase in livestock density in the Mediterranean landscapes, which as a consequence are heavily overgrazed (Petanidou and Ellis 1996, Petanidou et al. 2008, Kizos et al. 2010). Our results show that moderate grazing by sheep and/or goats increases the size, generalization, diversity, and complexity of the plant-flower visitor networks, which could in turn confer stability to Mediterranean communities. This study highlights the benefit of maintaining moderate levels of livestock grazing by sheep and/or goats to preserve the complexity and biodiversity of species-rich Mediterranean communities with a long history of grazing.

\section{ACKNOWLEDGEMENTS}

The research has been co-financed by the European Union (European Social Fund-ESF) and Greek National funds through the Operational Program "Education and Lifelong Learning" of the National Strategic Reference Framework (NSRF) - Research Funding Program: THALES: Investing in knowledge society through the European Social Fund. We would like to thank H. Dathe, J. Dils, A. Ebmer, D. Michez, A. Müller, A. Pauly, S. Patiny, C. Praz, S. Risch, W. Schedl, E. Scheuchl, M. Schwarz, and A. Vujic for insect identification. Thanks also to A. Vanbergen, C. Tur, M. Hidalgo, M. Devoto, and A. Traveset for their valuable advices during data analysis. We also thank the board of directors of The Natural History Museum of the Lesvos Petrified Forest for letting us install sites Sigri 2 and 3 in Lesvos Petrified Forest Park.

The title of this paper, "Moderation is best," has been inspired

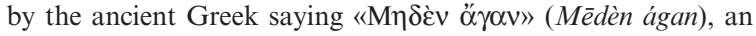
inscription in the front of the temple of Apollo at Delphi, and

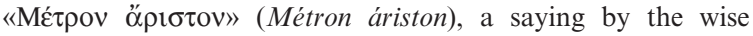
Kleovoulos from Rhodos, 6th century BC.

\section{Literature Cited}

Aizen, M. A., C. L. Morales, and J. M. Morales. 2008. Invasive mutualists erode native pollination webs. Plos Biology 6(2):e31.

Aizen, M. A., M. Sabatino, and J. M. Tylianakis. 2012. Specialization and rarity predict non-random loss of interactions from mutualistic networks. Science 335:1486-1489.

Almeida-Neto, M., and W. Ulrich. 2011. A straightforward computational approach for measuring nestedness using quantitative matrices. Environmental Modelling and Software 26:173-178.

Almeida-Neto, M., R. D. Loyola, W. Ulrich, P. Guimaraes, and P. R. Jr Guimaraes. 2008. A consistent metric for nestedness analysis in ecological systems: reconciling concept and measurement. Oikos 117:1227-1239.

Bascompte, J., P. Jordano, C. J. Melian, and J. M. Olesen. 2003. The nested assembly of plant-animal mutualistic networks. Proceedings of the National Academy of Sciences of the United States of America 100:9383-9387.

Bascompte, J., P. Jordano, and J. M. Olesen. 2006. Asymmetric coevolutionary networks facilitate biodiversity maintenance. Science 312:431-433.

Bastolla, U., M. A. Fortuna, A. Pascual-García, A. Ferrera, B. Luque, and J. Bascompte. 2009. The architecture of mutualistic networks minimizes competition and increases biodiversity. Nature 458:1018-1021.

Bersier, L. F., P. Dixon, and G. Sugihara. 1999. Scale-invariant or scale-dependent behaviour of the link density property in food webs: a matter of sampling effort? American Naturalist 153:676-682.

Bersier, L. F., C. Banasek-Richter, and M. F. Cattin. 2002. Quantitative descriptors of food-web matrices. Ecology 83:2394-2407.

Bjørnstad, O. N., and W. Falck. 2001. Non-parametric spatial covariance functions: estimation and testing. Environmental and Ecological Statistics 8:53-70.

Blondel, J., J. C. Aronson, J.-Y. Bodiou, and G. Boeuf. 2010. The Mediterranean region - biological diversity through time and space. Oxford University Press, Oxford, NY.

Blüthgen, N. 2010. Why network analysis is often disconnected from community ecology: a critique and an ecologist's guide. Basic and Applied Ecology 11(3):185-195.

Blüthgen, N., and A.-M. Klein. 2011. Functional complementarity and specialisation: the role of biodiversity in plantpollinator interactions. Basic and Applied Ecology 12:282-291.

Blüthgen, N., F. Menzel, and N. Blüthgen. 2006. Measuring specialization in species interaction networks. BMC Ecology 6:9.

Burnham, K. P., and D. R. Anderson. 2004. Multimodel inference: understanding AIC and BIC in Mo del Selection. Sociological Methods \& Research 33:261-304.

Conell, J. H. 1978. Diversity in tropical rain forests and coral reefs: high diversity of trees and corals is maintained only in a non-equilibrium state. Science 199:1302-1310.

Dalsgaard, B., et al. 2013. Historical climate-change influences modularity and nestedness of pollination networks. Ecography 36:1331-1340.

Davis, P.H. 1965-1985. Flora of Turkey and the east Aegean Islands, 1-9. Edinburgh University Press, Edinburgh.

Devoto, M., S. Bailey, P. Craze, and J. Memmott. 2012. Understanding and planning ecological restoration of plantpollinator networks. Ecology Letters 15:319-328.

Domínguez-García, V., and M. A. Muñoz. 2015. Ranking species in mutualistic networks. Scientific Reports 5:8182.

Dormann, C. F. 2011. How to be a specialist? Quantifying specialisation in pollination networks. Network Biology $1: 1-20$.

Dormann, C. F., and R. Strauss. 2014. A method for detecting modules in quantitative bipartite networks. Methods in Ecology and Evolution 5:90-98.

Dormann, C. F., B. Gruber, and J. Fruend. 2008. Introducing the bipartite package: analysing ecological networks. R News 8(2):8-11.

Dormann, C. F., J. Frund, N. Blughgen, and B. Gruber. 2009. Indices, graphs and null models: analyzing bipartite 
ecological networks. The Open Ecology Journal 2: $7-24$.

Dunne, J. A., R. J. Williams, and N. D. Martinez. 2002. Network structure and biodiversity loss in food webs: robustness increases with connectance. Ecology Letters 5:558-567.

Goldwasser, L., and J. Roughgarden. 1997. Sampling effects and the estimation of food-web properties. Ecology 78:41-54.

Gonçalves, P., S. Alcobia, L. Simoes, and M. Santos-Reis. 2012. Effects of management options on mammal richness in a Mediterranean agro-silvo-pastoral system. Agroforestry Systems 85:383-395.

Gotelli, N. J., and R. K. Colwell. 2001. Quantifying biodiversity: procedures and pitfalls in the measurement and comparison of species richness. Ecology Letters 4:379-391.

Grime, J. P. 1973. Competitive exclusion herbaceous vegetation. Nature 242:344-347.

Hurvich, C. M., and C.-L. Tsai. 1989. Regression and time series model selection in small samples. Biometrika 76:297-307.

James, A., J. W. Pitchford, and M. J. Plank. 2012. Disentangling nestedness from models of ecological complexity. Nature 487:227-230.

Kaltsas, D., A. Trichas, K. Kougioumoutzis, and M. Chatzaki. 2013. Ground beetles respond to grazing at assemblage level, rather than species-specifically: the case of Cretan shrublands. Journal of Insect Conservation 17:681-697.

Kati, V., K. Zografou, E. Tzirkalli, T. Chitos, and L. Willemse. 2012. Butterfly and grasshopper diversity patterns in humid Mediterranean grasslands: the roles of disturbance and environmental factors. Journal of Insect Conservation 16:807-818.

Kimoto, C., S. J. DeBano, R. W. Thorp, R. V. Taylor, H. Schmalz, T. DelCurto, T. Johnson, P. L. Kennedy, and S. Rao. 2012. Short-term responses of native bees to livestock and implications for managing ecosystem services in grasslands. Ecosphere 3:1-15.

Kizos, T., A. Dalaka, and T. Petanidou. 2010. Farmers' attitudes and landscape change: evidence from the abandonment of terraced cultivations on Lesvos, Greece. Agriculture and Human Values 27:199-212.

Koniak, G., and I. Noy-Meir. 2009. A hierarchical, multiscale, management-responsive model of Mediterranean vegetation dynamics. Ecological Modelling 220:1148-1158.

Krause, A. E., K. A. Frank, D. M. Mason, R. E. Ulanowicz, and W. W. Taylor. 2003. Compartments revealed in foodweb structure. Nature 426:282-285.

Lázaro, A., T. Tscheulin, J. Devalez, G. Nakas, and T. Petanidou. 2016. Effects of grazing intensity on pollinator abundance and diversity, and on pollination services. Ecological Entomology. In press. DOI: 10.1111/een.12310

Lewinsohn, T. M., P. I. Prado, P. Jordano, J. Bascompte, and J. M. Olesen. 2006. Structure in plant-animal interaction networks. Oikos 113:174-184.

Lopezaraiza-Mikel, M. E., R. B. Hayes, M. R. Whalley, and J. Memmott. 2007. The impact of an alien plant on a native plant-pollinator network: an experimental approach. Ecology Letters 10:539-550.

Marrero, H. J., J. P. Torretta, and D. Medan. 2014. Effect of land use intensification on specialization in plant-floral visitor interaction networks in the Pampas of Argentina. Agriculture, Ecosystems and Environment 188:63-71.

Martín González, A., B. Dalsgaard, and J. M. Olesen. 2010. Centrality measures and the importance of generalist species in pollination networks. Ecological Complexity 7:36-43.
Mayer, C., G. Soka, and M. Picker. 2006. The importance of monkey beetle (Scarabaeidae: Hopliini) pollination for Aizoaceae and Asteraceae in grazed and ungrazed areas at Paulshoek, Succulent Karoo, South Africa. Journal of Insect Conservation 10:323-333.

Medan, D., A.M. Basilio, M. Devoto, N.J. Bartolini, J.P. Torretta and T. Petaniou. 2006. Measuring generalization and connectance in temperate, long-lasting systems. Pages 245-259 in N.M. Waser, and J. Ollerton, editors. Plantpollinator interactions. From specialization to generalization. University Chicago Press, Chicago, IL.

Memmott, J., N. M. Waser, and M. V. Price. 2004. Tolerance of pollination networks to species extinctions. Proceedings of the Royal Society B 271:2605-2611.

Memmott, J., P. G. Craze, N. M. Waser, and M. V. Price. 2007. Global warming and the disruption of plant-pollinator interactions. Ecology Letters 10:710-717.

Michener, C. D. 1979. Biogeography of the bees. Annals of the Missouri Botanical Garden 66:277-347.

Migongobake, W., and R. M. Hansen. 1987. Seasonal diets of camels, cattle, sheep, and goats in a common range in Eastern-Africa. Journal of Range Management 40:76-79.

Murray, T. E., U. Fitzpatrick, A. Byrne, R. Fealy, M. J. F. Brown, and R. J. Paxton. 2012. Local-scale factors structure wild bee communities in protected areas. Journal of Applied Ecology 49:998-1008.

Navarro, T., C. L. Alados, and B. Cabezudo. 2006. Changes in plant functional types in response to goat and sheep grazing in two semi-arid shrublands of SE Spain. Journal of Arid Environments 64:298-322.

Naveh, Z., and R. H. Whittaker. 1979. Structural and floristic diversity of shrublands and woodlands in northern Israel and other Mediterranean areas. Vegetatio 41:171-190.

Nielsen, A., and Ø. Totland. 2014. Structural properties of mutualistic networks withstand habitat degradation while species functional roles might change. Oikos 123:323-333.

Nielsen, A., et al. 2011. Assessing bee species richness in two Mediterranean communities: importance of habitat type and sampling techniques. Ecological Research 26:969-983.

Okuyama, T., and J. N. Holland. 2008. Network structural properties mediate the stability of mutualistic communities. Ecology Letters 11:208-216.

Olesen, J. M., J. Bascompte, Y. L. Dupont, and P. Jordano. 2007. The modularity of pollination networks. Proceedings of the National Academy of Sciences 104(50):19891-19896

Olesen, J. M., J. Bascompte, Y. L. Dupont, H. Elberling, C. Rasmussen, and P. Jordano. 2011. Missing and forbidden links in mutualistic networks. Proceedings of the Royal Society of London B: Biological Sciences 278:725-732.

Petanidou, T., and W. N. Ellis. 1993. Pollinating fauna of a phryganic ecosystem: composition and diversity. Biodiversity Letters 1:9-22.

Petanidou, T., and W. N. Ellis. 1996. Interdependence of native bee faunas and floras in changing Mediterranean communities. Pages 201-226 in A. Matheson, S. L. Buchmann, C. O'Toole, P. Westrich and I. H. Williams, editors. The conservation of bees. Academic press, London.

Petanidou, T., T. Kizos, and N. Soulakellis. 2008. Socioeconomic dimensions of the agricultural landscape change in the Mediterranean: the case of the abandonment of cultivation terraces on Nisyros island, Greece. Environmental Management 41:250-266.

Petanidou, T., G. Ståhls, A. Vujić, J. M. Olesen, S. Rojo, A. Thrasyvoulou, S. Sgardelis, A. S. Kallimanis, S. Kokkini, and T. Tscheulin. 2013. Investigating plant-pollinator 
relationships in the Aegean: the approaches of the project POL-AEGIS (The pollinators of the Aegean archipelago: diversity and threats). Journal of Apicultural Research 52(2):106-117.

Pocock, M. J. O., O. Johnson, and D. Wasiuk. 2011. Succinctly assessing the topological importance of species in flowerpollinator networks. Ecological Complexity 8:265-272.

Potts, S.G., B. Vulliamy, A. Dafni, G. Ne'eman and P. Willmer. 2003. Linking bees and flowers: how do floral communities structure pollinator communities? Ecology 84:2628-2642.

Potts, S. G., T. Petanidou, S. Roberts, C. O'Toole, A. Hulbert, and P. G. Willmer. 2006. Plant-pollinator biodiversity and pollination services in a complex Mediterranean landscape. Biological Conservation 129:519-529.

Pykäla, J. 2004. Cattle grazing increases plant species richness of most species trait groups in mesic semi-natural grasslands. Plant Ecology 175:217-226.

Quinn, G. P., and M. J. Keough. 2002. Experimental design and data analysis for Biologists. Cambridge University Press, Cambridge, UK.

R Development Core Team. 2008. R: a language and environment for statistical computing. R Foundation for Statistical Computing, Vienna. ISBN 3-900051-07-0, http:// www.r-project.org.

Roulston, T. H., and K. Goodell. 2011. The role of resources and risks in regulating wild bee populations. Annual Review of Entomology 56:293-312.

Sjödin, N. E., J. Bengtsson, and B. Ekbom. 2008. The influence of grazing intensity and landscape composition on the diversity and abundance of flower-visiting insects. Journal of Applied Ecology 45:763-772.

Thébault, E., and C. Fontaine. 2010. Stability of ecological communities and the architecture of mutualistic and trophic networks. Science 329:853-856.

Tylianakis, J. M., E. Laliberté, A. Nielsen, and J. Bascompte. 2010. Conservation of species interaction networks. Biological Conservation 143:2270-2279.

Ulrich, W., M. Almeida-Neto, and N. J. Gotelli. 2009. A consumer's guide to nested analysis. Oikos 118:3-17.

Vanbergen, A. J., B. A. Woodcock, A. Gray, F. Grant, A. Telford, P. Lambdon, D. S. Chapman, R. F. Pywell, M.
S. Heard, and S. Cavers. 2014. Grazing alters insect visitation networks and plant mating systems. Functional Ecology 28:178-189.

Vázquez, D. P., and D. Simberloff. 2003. Changes in interaction biodiversity induced by an introduced ungulate. Ecology Letters 6:1077-1083.

Vázquez, D. P., C. J. Melián, N. M. Williams, N. Blügthen, B. R. Krasnov, and R. Poulin. 2007. Species abundance and asymmetric interaction strength in ecological networks. Oikos 116:1120-1127.

Vázquez, D. P., N. Blügthen, L. Cagnolo, and N. P. Chacoff. 2009. Uniting pattern and process in plant-animal mutualistic networks: a review. Annals of Botany 103:1445-1457.

Vieira, M.C. and M. Almeida-Neto. 2015. A simple stochastic model for complex coextinctions in mutualistic networks: robustness decreases with connectance. Ecology Letters 18:144-152.

Vieira, M. C., M. V. Cianciaruso, and M. Almeida-Neto. 2013. Plant-pollinator coextinctions and the loss of plant functional and phylogenetic diversity. PLoS ONE 8(11):e81242.

Vulliamy, B., S. G. Potts, and P. G. Wilmer. 2006. The effects of cattle grazing on plant-pollinator communities in a fragmented Mediterranean landscape. Oikos 114:529-543.

Welti, E. A. R., and A. Joern. 2015. Structure of trophic and mutualistic networks across broad environmental gradients. Ecology and Evolution 5(2):326-334.

Xie, Z., P. H. Williams, and Y. Tang. 2008. The effect of grazing on bumblebees in the high rangelands of the eastern Tibetan Plateau of Sichuan. Journal of Insect Conservation 12:695-703.

Yoshihara, Y., B. Chimeddorj, B. Buuveibaatar, B. Lhagvasuren, and S. Takatsuki. 2008a. Effects of livestock grazing on pollination on a steppe in eastern Mongolia. Biological Conservation 141:2376-2386.

Yoshihara, Y., T. Y. Ito, B. Lhagvasuren, and S. Takatsuki. 2008b. A comparison of food resources by Mongolian gazelles and sympatric livestock in three areas in Mongolia. Journal of Arid Environments 72:48-55.

Zuur, A. F., E. N. Ieno, N. J. Walker, A. A. Saveliev, and G. M. Smith. 2009. Mixed effects models and extensions in ecology with R. Springer, New York, NY.

\section{Data Availability}

Data associated with this paper have been deposited in Dryad: http://dx.doi.org/10.5061/dryad.p3c75 